University of Louisville

ThinkIR: The University of Louisville's Institutional Repository

Faculty Scholarship

$7-2013$

\title{
A randomized controlled trial of a cognitive-behavioral program for the prevention of depression in adolescents compared to nonspecific and no-intervention control conditions.
}

\author{
Patrick Pössel \\ University of Louisville \\ Nina C. Martin \\ Vanderbilt University \\ Judy Garber \\ Vanderbilt University \\ Martin Hautzinger \\ Eberhard-Karls-Universitat Tubingen
}

Follow this and additional works at: https://ir.library.louisville.edu/faculty

Part of the Counseling Psychology Commons

Original Publication Information

Pössel, Patrick, Nina C. Martin, Judy Garber and Martin Hautzinger. "A Randomized Controlled Trial of a Cognitive-Behavioral Program for the Prevention of Depression in Adolescents Compared to Nonspecific and No-Intervention Control Conditions." 2013. Journal of Counseling Psychology 60(3): 432-438.

This Article is brought to you for free and open access by ThinkIR: The University of Louisville's Institutional Repository. It has been accepted for inclusion in Faculty Scholarship by an authorized administrator of ThinkIR: The University of Louisville's Institutional Repository. For more information, please contact thinkir@louisville.edu. 
A Randomized Controlled Trial of a Cognitive-Behavioral Program for the Prevention of Depression in Adolescents Compared to Nonspecific and No-Intervention Control Conditions

\author{
Patrick Pössel, Nina C. Martin, Judy Garber, \\ Vanderbilt University, Nashville, TN, USA \\ and Martin Hautzinger \\ Eberhard-Karls-University, Tübingen, Germany
}

\begin{abstract}
Author Note
Patrick Pössel is now at the University of Louisville, Kentucky.

We wish to thank the students, teachers, and school staff for their participation and assistance in making this study possible. This research was supported by a grant to Patrick Pössel and Martin Hautzinger from the German Research Foundation. Judy Garber was supported in part by an Independent Scientist Award from the National Institute of Mental Health (K02 MH66249).
\end{abstract}

Correspondence concerning this article should be addressed to Patrick Pössel, Dr. rer. soc., Dep. of Educational and Counseling Psychology, University of Louisville, 2301 S. Third Street, Louisville, KY 40292, USA, e-mail: patrick.possel@ louisville.edu 


\begin{abstract}
Adolescent depression is a common and recurrent disorder associated with significant impairment and other forms of psychopathology. Finding an effective intervention that prevents depression in adolescents is an important public health priority. Participants were 518 high school students (mean age $=15.09 ; S D=0.76$ ) from the mid-south of the United States. Participants were randomly assigned to one of three conditions: a cognitivebehavioral program $(\mathrm{CB} ; \mathrm{n}=166)$, nonspecific control $(\mathrm{NSp} ; \mathrm{n}=175)$, or a no-intervention control condition (NIC; $\mathrm{n}=177$ ). Both the CB and NSp conditions consisted of 90-minute sessions administered once a week over a 10-week period during regular school hours. Depressive symptoms were assessed with the Children's Depression Inventory (CDI) at baseline, post-intervention, and at 4-, 8-, and 12-month follow-ups. The time by condition interaction was significant $[F(8,478.57)=3.32, p=.001]$ indicating that at the 4-month follow-up, youth in the CB condition had significantly lower CDI scores compared to those in the NSp $(p=0.047, g=0.29 ; C I: 0.06-0.52)$ and the NIC conditions $(p=0.003, g=0.30 ; C I$ : 0.07-0.53). Future studies need to examine the importance of theory-driven change mechanisms, interpersonal relationships, and structural circumstances in schools as factors impacting the long-term effects of CB prevention programs.
\end{abstract}

Keywords: school-based prevention; depression; adolescents 
The first onset of major depression often occurs during adolescence (Hankin et al., 1998) and is associated with increased risk of recurrent depressive episodes (Rutter, Caspi, \& Moffitt, 2003) and other psychopathology into adulthood (Birmaher et al., 1996). Therefore, finding an effective intervention that prevents depression in adolescents is an important public health priority.

Meta-analyses of studies aimed at preventing depression in children and adolescents have concluded that some efficacious interventions for the prevention or reduction of depressive symptoms in youth exist (e.g., Brunwasser, Gillham, \& Kim, 2009; Horowitz \& Garber, 2006; Merry, Hetrick, Cox, Brudevold-Iversen, Bir, \& McDowell, 2011; Stice, Shaw, Bohon, Marti, \& Rohde, 2009). On average, effect sizes (ES) of the various depression prevention programs have been small to modest. Moderators of these effects have included the type of sample (i.e., universal, selective, indicated), participant attributes (e.g., age, sex, race), characteristics of the intervention (e.g., duration, content) and interventionists (e.g., level of training), and timing of assessments (e.g., post-intervention, follow-ups of various lengths). ESs also differ depending on the type of comparison group used, with greater ESs when contrasted with a no intervention or waitlist control and lower ESs when compared to an active or placebo control (Cuijpers, van Straten, Smit, Mihalopoulos, \& Beekman, 2008).

Meta-analyses of the psychotherapy literature have shown that nonspecific processes account for about half the effects of specific interventions such as cognitive-behavioral therapy (CBT; Baskin, Tierney, Minami, \& Wampold, 2003; Stevens, Hynan, \& Allen, 2000). Further, Baskin et al. (2003) found similar effects for specific (e.g., CBT) and nonspecific programs when they had structural equivalence regarding the number and duration of sessions, settings (group vs. individual), level of therapists' experience, and adaptability of the therapy to the client. Baskin and associates argued that the efficacy of specific programs was due mostly to such nonspecific processes. A recent meta-analysis of studies of therapy for depression in adults found that nonspecific processes were responsible for almost $50 \%$ of 
therapy effects, whereas specific factors accounted for only $17 \%$ of the effects (Cuijpers, Driessen, Hollon, van Oppen, Barth, \& Andersson, 2012).

Examination of nonspecific processes has been less common in randomized control trials (RCTs) of depression prevention programs. Most depression prevention studies in adolescents have compared a specific intervention to a no-intervention or waitlist control (Merry et al., 2011). Only a few trials have compared a specific prevention program with a nonspecific control condition (Merry, McDowell, Wild, Bir, \& Cunliffe, 2004; Pössel, Horn, \& Hautzinger, 2006; Stice, Rohde, Seeley, \& Gau, 2008). Merry and colleagues (2004) reported that the specific school-based Resourceful Adolescent Program (RAP; Shochet et al., 2001) was more effective than a nonspecific control in the short-term but not at follow-up; the effect size was small and the findings were not consistent across depression measures. The Penn Resiliency Program (PRP) repeatedly has been shown to be more effective than a nointervention control (Brunwasser et al., 2009) but has not been significantly better at reducing or preventing depressive symptoms in middle school students when compared to an alternative intervention (Gillham et al., 2007).

Using a universal prevention design, Pössel et al. (2006) demonstrated that $8^{\text {th }}$ grade students participating in a cognitive-behavioral (CB) prevention program (LARS\&LISA [Lust An Realistischer Sicht \& Leichtigkeit Im Sozialen Alltag Lust; translated as Desire for a Realistic View and Ease in Social Aspects of Everyday Life]) showed a significant decrease in depressive symptoms compared to their peers participating in an "expressive writing" intervention (Pennebaker, 1997) and a no-intervention control condition at both postintervention and the 3-month follow-up. One limitation of this study, however, was that the durations of the expressive writing program (i.e., six 45-minute sessions) and the CB program (i.e., ten 90-minute sessions) were different from each other. Thus, the expressive writing program did not fulfill the requirement of a structurally equivalent condition (Baskin et al., 2003). Stice et al. (2008, 2010) addressed some of the limitations of the studies by Merry et 
al. (2004) and Pössel et al. (2006) by comparing a six-session CB program with a supportiveexpressive program, which was structurally equivalent but had different content, and a nointervention, waitlist control group in an indicated sample of high school students. Participants in the $\mathrm{CB}$ condition showed a significantly greater decrease in depressive symptoms from baseline to post-intervention and from baseline to 6-month follow-up compared to those in the waitlist control group (Stice et al., 2008) and a significantly greater decrease in depressive symptoms from baseline to post-intervention but not from baseline to the 6-, 12-, or 24-month follow-up compared to those in the supportive-expressive program (Stice et al., 2008, 2010).

Thus, the results of studies addressing the specificity question are inconclusive. Indeed, in the most thorough review of this literature to date, Merry and colleagues (2011) concluded that "There was no evidence of efficacy in the few studies that compared intervention with placebo or attention controls" (p. 1414). Therefore, Merry et al. asserted that "Future studies should test efficacy against a credible alternative to address the gap that remains concerning possible placebo effect” (p. 1442). Without explicitly contrasting the specific prevention program with a nonspecific control condition, it is not possible to know whether observed effects are attributable to the specific intervention methods per se, nonspecific factors common to both conditions (e.g., attention), or design artifacts (e.g., demand characteristics). Such comparisons can help to identify and enhance components that work and eliminate those that do not, thereby creating more powerful and cost-effective interventions (Kraemer, Wilson, Fairburn, \& Agras, 2002).

The current study directly addressed the specificity issue and built on previous literature in several ways. First, in contrast to the trial by Pössel et al. (2006), in the current study the durations of the CB and nonspecific programs were identical. Second, this study included an assessment-only control condition that did not receive any intervention, thereby allowing us to determine whether no differences (null findings) between the specific and 
nonspecific intervention were due to their both being effective or both being ineffective.

Third, beyond the most extensive test of nonspecific depression prevention approaches conducted by Stice and colleagues (2008), the current study was a particularly stringent test of specificity by including a credible comparison program that was equivalent not only in structure but also in content. That is, the topics covered during each session in each program were similar; only the information and skills conveyed were different (see the Online Supplement for a description of the programs).

Thus, the present study compared a CB, school-based program, LARS\&LISA (Pössel, Horn, Seemann, \& Hautzinger, 2004), to two different control conditions with regard to adolescents' depressive symptoms at multiple time points over 12 months. One condition was a structurally and topically equivalent nonspecific control and the other was a nointervention control. We hypothesized that the CB program would produce significantly lower levels of depressive symptoms at post-intervention as compared to the nonspecific control (NSp) and the no-intervention control (NIC) conditions and would have a significant sustained effect compared to the other two conditions.

\section{Methods}

\section{Participants}

Participants were 518 students (mean age $=15.09$ years; $S D=0.76$ ) in Wellness classes at a high school in the mid-south of the United States; $62.7 \%$ were female. The sample was 72.8\% Caucasian, 14.7\% African-American, 5.4\% Latino, 1.4\% Asian/Pacific Islander, 0.8\% Native American, 4.4\% Mixed Heritage, and 0.6\% Other. Census data indicated that the school serves communities characterized as predominantly working to middle class. According to county data, $29 \%$ of the students were eligible for free or reduced-price lunches.

Participants were randomly assigned by Wellness class to one of three conditions: the CB program, the nonspecific control (NSp), or the no-intervention control (NIC) condition. 
Wellness class is typically taken in $9^{\text {th }}$ grade and is state-mandated for all students in regular academic classes within the school district in which the study was conducted. Wellness classes do not differ from one another in terms of students' academic level or educational aspirations. To eliminate any potential systematic effects of class period, randomization to conditions varied across the days, times, and time of year (spring versus fall) from semester to semester. Demographic characteristics of students in the three conditions are presented in Table 1.

Over the course of the follow-up period, $12 \%$ of the total sample was not available for evaluation mainly due to their having changed schools during the study. No significant differences were found between the unavailable and the remaining students as a function of condition, $\chi^{2}(2)=1.60, p=.450$, race/ethnicity, $\chi^{2}(6)=8.83, p=.183$, or severity of depressive symptoms at baseline, $t(513)=-1.15, p=.251$. Unavailable students were significantly older than those who remained, $t(68.17)=-5.31, p<.001$, and were somewhat more likely to be male, $\chi^{2}(1)=3.73, p=.053$.

\section{Measure}

Severity of depressive symptoms was assessed with the Children's Depression Inventory (CDI, Kovacs, 1981), a 26-item measure of cognitive, affective, and behavioral symptoms of depression (the suicide item was removed at the request of the school, as is common in school-based research). Each item lists three statements, scored 0 through 2, in order of severity. Respondents rate each CDI item according to how much they have experienced each depressive symptom in the past two weeks. The CDI differentiates between normal and clinically depressed youth (Carey, Faulstich, Gresham, Ruggiero, \& Enyart, 1987) and has good test-retest reliability, internal consistency, and construct validity, especially in nonclinical samples (Sitarenios \& Kovacs, 1999). In the current sample, internal consistency of the CDI ranged from $\alpha=.91$ to .93 across the five assessments. 
Adherence to the LARS\&LISA and the NSp manuals was assessed using checklists of the intended content of the individual sessions (e.g., "explained thinking errors," "discussed feelings"). After each session, group leaders independently recorded what content had been covered in the session $(0=$ not covered, $1=$ partially covered, $2=$ completely covered $)$. The average rating across all sessions for all raters was $1.83(S D=0.09)$ for the LARS\&LISA sessions and $1.85(S D=0.12)$ for the NSp sessions. Inter-rater reliability across all sessions was $r=.62$ for the LARS\&LISA program and $r=.79$ for the NSp condition.

\section{The Cognitive-Behavioral Program: LARS\&LISA}

The manualized school-based prevention program, LARS\&LISA, was originally developed in Germany (Pössel, Horn, Seemann et al., 2004) and was modified for youth in the United States. Modifications included constructing culturally appropriate role plays for American students in which relevant idiomatic expressions were used and otherwise tailoring the program for use by American youth. The LARS\&LISA intervention is based on the social information processing (SIP) model (Dodge, 1993) and uses various methods from CBT (Beck, Rush, Shaw, \& Emery, 1979). Cognitive and social components of the social information processing model are targeted as follows: (a) four cognitive sessions focus on understanding the relations among cognitions, emotions, and behaviors and teach how to identify and challenge negative cognitions; and (b) four social sessions train participants in assertiveness and social competence skills (for a description of the links between the SIP and LARS\&LISA, see Pössel, Adelson, \& Hautzinger, 2011). In addition, the first session outlines the rationale for the program, and the $10^{\text {th }}$ session is a review and celebration.

\section{The Nonspecific Control Condition (NSp)}

The NSp condition was structurally equivalent (Baskin et al., 2003) to the LARS\&LISA program in the following ways: (a) ten 90-minute weekly sessions, (b) gender homogenous groups, (c) two group leaders, (d) similar content areas (see Online Supplement), (e) similar amount of attention from group leaders, and (f) similar degree of 
training and supervision of group leaders. The primary difference between the LARS\&LISA and the NSp program was that the latter did not convey any information about the cognitivebehavioral model or teach specific cognitive or social skills. Instead, NSp used basic supportive humanistic strategies with more broad-based and open-ended conversations (e.g., a discussion about what emotions are without connecting feelings to thoughts or behaviors).

\section{The No Intervention Control (NIC)}

Students randomized to the NIC condition remained in their regular Wellness class, which was the same duration as the CB and NSp conditions. Wellness classes included discussions about health, nutrition, sleep, and exercise. Control students participated in the same assessments at each time point as those in the CB and NSp conditions.

\section{Design and Procedure}

Letters describing the study were sent to parents of students in all Wellness classes each semester. Students who received parental consent were invited to participate and asked for their assent. Both interventions were described to students, teachers, and parents as probably efficacious. Assessments were conducted in group sessions one week before the intervention began (baseline), one week after the intervention ended (post-intervention), and at 4,8 , and 12 months post intervention. The study was approved by the University Institutional Review Board for the Protection of Human Subjects.

As in an earlier study of the LARS\&LISA program (Pössel, Horn, \& Hautzinger, 2003), we used separate, same-sex groups in the CB and the NSp conditions to maintain structural equivalence across programs. Both males and females have been found to be more likely to share their feelings and to be more self-disclosing in same-sex versus mixed-sex groups, especially when the intervention includes a social skills component (e.g., Warrington \& Younger, 2003).

A total of 63 classes participated. The $20 \mathrm{CB}$ and $19 \mathrm{NSp}$ groups were led by two facilitators, one designated as the group leader (Masters level or higher; $n=3$ ) and the other 
as co-leader (graduate students in clinical psychology or counseling psychology, $n=17$ ). All leaders were experienced in working with adolescents and trained in either a cognitivebehavioral or a humanistic counseling tradition (NSp). To ensure a similar level of therapist experience, which is one element of structural equivalence, each group was led by at least one group leader who was trained in and implemented both programs.

Training for each program was provided in two steps. First, group leaders participated in a mock version of the program with each other conducted by program supervisors (PP, JG, NCM). Second, they studied the manual, all materials, and procedures and resolved unclear points with the supervisors. Throughout the course of the intervention period, weekly supervision was provided to all group leaders by the supervisors, who watched video recordings of each session. Supervision meetings were held separately for co-leaders of LARS\&LISA and the NSp condition. To insure credibility of both programs for the leaders, the particular models underlying the CB and NSp programs were reviewed during supervision. In addition, group leaders were trained and supervised in both CB and humanistic skills; both programs were considered to be credible interventions.

\section{Data Analysis}

We conducted a 3-level analysis, with time points nested within students, and students nested within classes, using SPSS 20. We fit mixed models with repeated measures and the subcommand EMMEANS to calculate pairwise comparisons with Bonferroni tests (i.e., all reported analyses were automatically Bonferroni adjusted). The dependent variable in the analyses was the CDI total score. Condition (CB, NSp, NIC) and time (baseline, postintervention, 4, 8, and 12 months post intervention) and all interactions among these variables were entered as independent variables. Models with sex as an additional independent variable also were estimated. Neither the main effect nor any interactions with sex was significant; accordingly, analyses reported here did not include sex. 
Effect sizes were calculated following Hedges' g [= (mean of one group minus mean of the other group) divided by the pooled standard deviation of both groups]. A $g$ of 0.2 represents a small effect, 0.5 is a medium effect, and 0.8 is a large effect (Cohen, 1988). Hedges' g's are displayed as positive values when in line with the hypotheses and as negative values when counter to them.

\section{Results}

\section{Sample and Intervention Group Characteristics}

The three conditions (CB, NSp, NIC) did not differ significantly by age: $F(2$, $510)=0.43, p=0.65$; sex: $\chi^{2}(2)=0.42, \mathrm{p}=0.81$; race/ethnicity: $\chi^{2}(12)=10.81, \mathrm{p}=0.55$; or severity of depressive symptoms at baseline, $F(2,510)=0.60, \mathrm{p}=0.55$. No significant differences were found between the CB and NSp conditions regarding group size (CB: Mean=9.17, $S D=2.56$; NSp: Mean=9.75, $S D=3.53), t(338)=-1.62, p=.106$, manual adherence, $t(305.99)=-1.21$, $\mathrm{p}=0.23$, or students' attendance, $t(336)=-0.32, \mathrm{p}=0.75$ (see Table 1$)$. Group leaders' manual adherence was $91.6 \%$ in the $\mathrm{CB}$ condition (Mean=1.83, $S D=0.09$, range 1.60 to 2.00 ) and $92.4 \%$ in the NSp condition (Mean=1.85, SD=0.12, range 1.51 to 2.00 [2=100\% adherence]).

At baseline, severity of depressive symptoms on the CDI covered almost the full range of the scale (CDI range: 0 to 47). Table 2 presents the correlations among the CDI scores at each time point and the means and standard deviations by time point and condition.

\section{Effects of the CB Intervention on Depressive Symptoms}

Between-group comparisons. The time by condition interaction was significant, $F(8$, $478.57)=3.32, p=.001$, indicating that the effect of time on depressive symptom scores differed by condition. Comparisons between the CB condition and each of the two other conditions revealed a significant difference at the 4-month follow-up, such that CDI scores in the CB condition were significantly lower than those in both the NSp $(p=.047, g=0.29$; CI: 0.06-0.52) and the NIC conditions ( $\mathrm{p}=.003, \mathrm{~g}=0.30$; CI: 0.07-0.53). 
Within-group comparisons. Pairwise comparisons within the $\mathrm{CB}$ condition revealed that, compared to baseline, CDI scores were significantly higher at post-intervention $(p<.001$, $\mathrm{g}=-0.41$; CI: $-0.18--0.65)$ but significantly lower at the 4-month $(p<.001, \mathrm{~g}=0.31$; CI: 0.07$0.54)$ and 8-month follow-up evaluations ( $p=.002, \mathrm{~g}=0.30$; CI: 0.07-0.53) and marginally lower at the 12-month follow-up ( $p=.074, \mathrm{~g}=0.22$; CI: $-0.01-0.46)$, indicating that within the $\mathrm{CB}$ condition, depressive symptoms increased from baseline to post-intervention but declined significantly from baseline to 4-months and baseline to 8-months.

Within the NSp condition, pairwise comparisons revealed that, compared to baseline, CDI scores were significantly higher at post-intervention $(p<.001, \mathrm{~g}=-0.49 ; \mathrm{CI}$ :- 0.27- -0.72$)$ and significantly lower at the 8-month ( $p=.002, \mathrm{~g}=0.26$; CI: 0.03-0.48) and 12-month followups $(p<.001, \mathrm{~g}=0.34$; CI: $0.11-0.56)$, indicating that youth in the NSp condition experienced a significant increase in depressive symptoms immediately following the intervention and a decrease from baseline in CDI scores by the 8-month follow-up.

Within the NIC condition, pairwise comparisons revealed that relative to baseline, CDI scores were significantly lower at 8 -months $(p=.005, \mathrm{~g}=-0.32$; CI: $-0.10--0.55)$ and 12months $(p=.035, \mathrm{~g}=-0.28 ; \mathrm{CI} ;-0.05--0.50)$.

\section{Discussion}

The current randomized control trial tested the efficacy of a CB intervention for preventing depressive symptoms in adolescents as compared to a structurally and topically equivalent nonspecific control and a no-intervention control condition. The between-group analyses revealed that at the 4-month follow-up, adolescents in the CB condition reported significantly lower levels of depressive symptoms (CDI) as compared to youth in both the NSp and the NIC conditions. Within-group analyses indicated that for youth in the CB condition, CDI scores at 4 months were significantly lower than their scores at baseline; depression scores of adolescents in the NSp condition did not decrease significantly from baseline until the 8-month follow-up. In the NIC condition, depressive symptoms showed a 
significant decrease from baseline to the 8- and 12-month follow-ups. The decline in depressive symptoms across multiple assessments in all three conditions is consistent with other studies that have shown that in normative samples of youth, CDI scores tend to decline over time (Twenge \& Nolen-Hoeksema, 2002). Of particular note in the present study was the finding that depressive symptoms declined sooner for youth in the CB group as compared to those in either of the other two conditions. Thus, the significant decline in depressive symptoms in the $\mathrm{CB}$ condition at the 4-month follow-up, both compared to the other two control conditions and compared to within-group at baseline, indicates that teaching the specific cognitive and social skills, as in the CB program, is useful, at least in the short-term, for the prevention of depressive symptoms in adolescents.

Two other important conclusions can be drawn from the current randomized trial. First, the significant effect of the CB program at four months was not simply due to common, nonspecific factors (e.g., attention from a supportive adult), at least not those that characterized the NSp condition. Including a nonspecific comparison condition that was equivalent not only in structure and duration but also in content allowed for a more stringent test of the specificity question. Further studies are needed to determine the specific, active processes responsible for the positive effects of the $\mathrm{CB}$ prevention program, particularly those related to theoretically derived change mechanisms (e.g., Beck, 1967; Dodge, 1993).

A second important finding was that although the CB program had a significant positive effect compared to the NSp and NIC control conditions at the 4-month evaluation, these differences did not persist. The apparent absence of an enduring effect in the present study may have been partially due to the fact that the level of depressive symptoms decreased over time in the NIC condition as well. Prevention studies using universal samples depend on an increase in symptoms occurring in the no intervention control condition in order to demonstrate that the active intervention actually prevented a normative increase in symptoms (Horowitz \& Garber, 2006; Pössel, Horn, Groen, \& Hautzinger, 2004). If the level of 
reported depressive symptoms in the control condition does not increase, or even decreases, over time, then demonstrating the efficacy of an "active" intervention may be difficult and likely will require a larger effect size than was found here.

Another possible explanation for differences in the findings of the current study as compared to that of Pössel et al. (2011) may be cultural differences between German and American high schools or the manner in which the original LARS\&LISA program was modified for use with youth in the United States. For example, German schools have a school-cohort system in which a class of up to 30 students becomes a cohort within the school, taking all of their courses together. German students usually have most of their friends in one class, perhaps increasing the chance that the lessons learned in a prevention program will continue to be implemented; that is, the positive effects may be sustained as friends continue to talk about the content of the shared program even after it concludes.

In addition, the German LARS\&LISA program might have promoted interpersonal relationships by facilitating adolescents' sharing personal thoughts with each other within the smaller and more protected environment of their class (Sukhnandan, Lee, \& Kelleher, 2000). Such improved interpersonal relationships may have, in turn, helped the German students cope with stressors that occurred long after the prevention program ended. Indeed, Pössel and colleagues (2003) found that participation in a version of LARS\&LISA was associated with an increased reliance on social support in girls and an increase in the reported social networks of boys. Future studies should explore whether the inclusion of and emphasis on a social network component within a CB program might increase the efficacy of the program both immediately and over time.

Cultural differences between German and American schools also might explain why this study did not replicate the findings of Pössel et al. (2011) of a positive effect of LARS\&LISA up to 12 months after completion of the program. Studies conducted in the United States have found an increase in magnitude of effect sizes of prevention programs 
post-intervention to 6-month follow-up but then a decrease in the effect size with longer time lags between the end of the prevention program and later follow-up time points (for a review, see Pössel, Schneider, \& Seemann, 2006).

Finally, why depressive symptoms increased at post-intervention compared to baseline in both the CB and NSp conditions is unclear. Perhaps participation in one of the active interventions increased students' awareness of their problems and recognition of their feelings. Over the four months after the intervention, however, adolescents in the $\mathrm{CB}$ condition may have had the opportunity to practice and implement their newly acquired skills within the context of real-life problems and thereby experience positive benefits and lower symptom levels at later time points (Pössel et al., 2003). Another possible explanation for the higher scores at the post-intervention assessment for adolescents in both intervention conditions may be that they came to enjoy and value the social aspect, camaraderie, and adult support provided by the groups and thus reported higher depressive symptoms at the postintervention assessment as an expression of their disappointment that the group had ended.

The current RCT had several strengths, including a large sample, assessments across multiple time points over a 12-month period, relatively low attrition (12\%), and the use of fidelity checks. Additionally, the CB intervention was theoretically derived (e.g., Beck, 1967; Dodge, 1993) and carefully manualized. The inclusion of a structurally equivalent, nonspecific intervention, which also was manualized, allowed us to conduct a strict test of specificity; the no-intervention control facilitated interpretation of group comparisons.

Limitations of this study also should be noted. First, the primary outcome -depressive symptoms -- was measured with a single self-report inventory. Previous studies have shown that adolescents are reliable informants about their depression (Inderbitzen, 1994), and depression measured by self-report has high predictive validity (Gotlib, Lewinsohn, \& Seeley, 1995). Nevertheless, additional information from other self-report measures, psychiatric interviews, other sources (e.g., teachers, parents, peers), or behavioral 
observations should be used in future depression prevention trials. Second, given that the intervention might affect other outcomes (e.g., anxiety, behavior problems, functioning), measures of these constructs also should be included. Third, although the drop-out rates were not significantly different across the three conditions, a nonsignificant trend indicated that dropouts were more likely to be male and older than those who did not drop out. Therefore, generalizability of the findings to older male adolescents might be limited. Fourth, the theoretical mechanisms of change, such as social information processing (Dodge et al., 1993) or common, nonspecific factors (Imel \& Wampold, 2008), were not analyzed. Fifth, although both the CB and NSp conditions were structurally equivalent, thereby controlling for many nonspecific factors as noted earlier, we did not assess whether the interventions were similarly credible for the group leaders and participating students. The nonspecific control condition in the present study, however, met all three criteria cited by Stevens and colleagues (2000) as necessary for establishing the credibility of a nonspecific comparison condition: (a) the number of sessions in both interventions was equal; (b) a positive rationale or expectation for positive outcome was provided; and (c) the nonspecific intervention included a discussion of problems. Nevertheless, without explicitly measuring the plausibility of the interventions used here, we cannot know for certain if they were perceived to be comparably credible by the group leaders and participants.

In summary, the present RCT indicated that the $\mathrm{CB}$ program produced a significant depression prevention effect at four months that likely was not due simply to nonspecific factors. Evidence of specificity is considered to be a precursor to expensive dissemination efforts (e.g., Stice et al., 2008); therefore, identification of effective programs that may be suitable for roll-out is now a research priority (Merry et al., 2011). Future studies should identify what specific components of the CB program underlie its short-term effectiveness and determine how best to enhance the CB intervention so that these effects can be sustained. 


\section{References}

Baskin, T.W., Tierney, S.C., Minami, T., \& Wampold, B.E. (2003). Establishing specificity in psychotherapy: A meta-analysis of structural equivalence of placebo controls. Journal of Consulting and Clinical Psychology, 71, 973 - 979. doi: 10.1037/0022006X.71.6.973

Beck, A. T., Rush, A. J., Shaw, B. F., \& Emery, G. (1979). Cognitive therapy of depression. New York: The Guilford Press.

Birmaher B., Ryan N. D., Williamson, D. E., Brent, D. A., Kaufman, J., Dahl, R.E., ... Nelson, B. (1996). Childhood and adolescent depression: A review of the past 10 years. Part I. Journal of the American Academy of Child and Adolescent Psychiatry, $35,1427-1439$.

Brunwasser, S. M., Gillham, J. E., \& Kim, E. S. (2009). A meta-analytic review of the Penn Resiliency Program's effect on depressive symptoms. Journal of Consulting and Clinical Psychology, 77, 1042 - 1054. doi: 10.1037/a0017671

Carey, M.P., Faulstich, M.E., Gresham, F.M., Ruggiero, L., \& Enyart, P. (1987). Children's Depression Inventory: Construct and discriminant validity across clinical and non-referred (control) populations. Journal of Consulting and Clinical Psychology, 55, $755-761$.

Clarke, G. N., Hawkins, W., Murphy, M., \& Sheeber, L. (1993). School-based primary prevention of depressive symptomatology in adolescents. Findings from two studies. Journal of Adolescent Research, 8, 183-204.

Cohen, J. (1988). Statistical Power Analysis for the Behavioral Sciences. New York: Erlbaum.

Cuijpers, P., Driessen, E., Hollon, S. D., von Oppen, P., Barth, J., \& Andresson, G. (2012). The efficacy of non-directive supportive therapy for adult depression: a meta-analysis. Clinical Psychology Review, 32, 280-291. doi:10.1016/j.cpr.2012.01.003 
Cuijpers, P., van Straten, A., Smit, F., Mihalopoulos, C., \& Beekman, A. (2008). Preventing the onset of depressive disorders: A meta-analytic review of psychological interventions. American Journal of Psychiatry, 165, 1272-1280. doi: 10.1037/a0013075

Dodge, K. A. (1993). Social-cognitive mechanisms in the development of conduct disorder and depression. Annual Review of Psychology, 44, 559 - 584.

Garber, J., Weiss, B., \& Shanley, N. (1993). Cognitions, depressive symptoms, and development in adolescents. Journal of Abnormal Psychology, 102, 47-57.

Gillham, J. E., Reivich, K. J., Freres, D. R., Chaplin, T. M., Shatte, A. J., Samuels, B., Elkon, A. G. L., Litzinger, S., Lascher, M., Gallop, R., \& Seligman, M. E. P. (2007). Schoolbased prevention of depressive symptoms: a randomized controlled study of the effectiveness and specificity of the Penn Resliency Program. Journal of Consulting and Clinical Psychology, 75, 9-19. doi: 10.1037/0022-006X.75.1.9

Goldstein, H. (1995). Multilevel statistical models (2 ${ }^{\text {nd }}$ ed.). London: Arnold.

Gotlib, I. H., Lewinsohn, P. M., \& Seeley, J. R. (1995). Symptoms versus a diagnosis of depression: Differences in psychosocial functioning. Journal of Consulting and Clinical Psychology, 63, 90-100.

Hankin, B. L., Abramson, L. Y., Moffitt, T. E., McGee, R., Silva, P. A., \& Angell, K. E. (1998). Development of depression from preadolescence to young adulthood: Emerging gender differences in a 10-year longitudinal study. Journal of Abnormal Psychology, 107, $128-140$.

Hopkins, K. D. (1982). The unit of analysis: Group means versus individual observations. American Educational Research Journal, 19, 5-18.

Horowitz, J. L. \& Garber, J. (2006). The prevention of depressive symptoms in children and adolescents: A meta-analytic review. Journal of Consulting and Clinical Psychology, 74, 401-415. doi: 10.1037/0022-006X.74.3.401 
Imel, Z. E., \& Wampold, B. E. (2008). The importance of treatment and the science of common factors in psychotherapy. Handbook of Counseling Psychology. (pp. 249266).

Inderbitzen, H. M. (1994), Adolescent peer social competence. A critical review of assessment methodologies and instruments. In T. H. Ollendick \& R. J. Prinz (Eds.), Advances in clinical child psychology, 16. New York, NY: Plenum Press.

Kanfer, F. H. \& Gaelick-Buys, L. (1991). Self-management methods. In F. H. Kanfer \& A. P. Goldstein (Eds.), Helping people change. New York, USA: Pergamon.

Kovacs, M. (1981). Rating scales to assess depression in school-aged children. Acta Paedopsychiatrica, 46, 305-315.

Kraemer, H.C., Wilson, G.T., Fairburn, C.G., \& Agras, W.S. (2002). Mediators and moderators of treatment effects in randomized clinical trials. Archives of General Psychiatry, 59, 877-884.

Merry, S.N., Hetrick, S. E., Cox, G. R., Brudevold-Iversen, T., Bir, J. J., \& McDowell, H. (2011). Psychological and educational interventions for preventing depression in children and adolescents. Cochrane Database of Systematic Reviews, 12. Article No.: CD003380. DOI: 10.1002/14651858.CD003380.pub3

Merry, S. N., McDowell, H., Wild, C. J., Bir, J.J., \& Cunliffe, R. (2004). A randomized placebo-controlled trial of a school-based depression prevention program. Journal of the American Academy of Child and Adolescent Psychiatry, 43, 538-547. doi: 10.1097/01.chi.0000117063.63530.68

Pennebaker, J.W. (1997). Writing about emotional experiences as a therapeutic process. Psychological Science, 8, $162-166$.

Pössel, P., Adelson, J. L., \& Hautzinger, M. (2011). A randomized trial to evaluate the course of effects of a program to prevent adolescent depressive symptoms over 12 months. Behaviour Research and Therapy, 49, 838-851. doi:10.1016/j.brat.2011.09.010 
Pössel, P., Baldus, C., Horn, A. B., Groen, G., \& Hautzinger, M. (2005). Influence of general self-efficacy on the effects of a school-based universal primary prevention program of depressed symptoms in adolescents: a randomized and controlled follow-up study. Journal of Child Psychology and Psychiatry, 46, 982-994. doi: 10.1111/j.14697610.2004.00395.x

Pössel, P., Horn, A. B., Groen, G., \& Hautzinger, M. (2004). School-based prevention of depressive symptoms in adolescents: a 6-month follow-up. Journal of the American Academy of Child and Adolescent Psychiatry, 43, 1003-1010. doi:

10.1097/01.chi.0000126975.56955.98

Pössel, P., Horn, A. B., \& Hautzinger M. (2003). Erste Ergebnisse eines Programms zur schulbasierte Prävention von depressiven Symptomen bei Jugendlichen [First results of a school-based prevention program of depressive symptoms in adolescents]. Zeitschrift für Gesundheitspsychologie, 11, 10-20. doi: 10.1026//0943-8149.11.1.10

Pössel, P., Horn, A. B., \& Hautzinger M. (2006). Vergleich zweier schulbasierter Präventionsprogramme von depressiven Symptomen bei Jugendlichen [Comparison of two school-based depression prevention programs for adolescents]. Zeitschrift für Klinische Psychologie und Psychotherapie, 35, 109-116. doi: 10.1026/16163443.35.2.109

Pössel, P., Horn, A. B., Seemann, S., \& Hautzinger, M. (2004). Trainingsprogramm zur Prävention von Depressionen bei Jugendlichen. LARS\&LISA: Lust An Realistischer Sicht \& Leichtigkeit Im Sozialen Alltag [A training to prevent depression among adolescents. LARS\&LISA: The joy of taking a realistic view \& easy-goingness in everyday social life]. Hogrefe, Germany: Göttingen.

Pössel, P., Schneider, S., \& Seemann, S. (2006). Effekte und Kosten universaler Praevention von Internalisierungsstoerungen bei Kindern und Jugendlichen [Effects and costs of 
universal prevention of internalization disorders in children and adolescents]. Verhaltenstherapie, 16, 201-210. doi: 10.1159/000094918

Rutter, M., Caspi, A., \& Moffitt, T. E. (2003). Using sex differences in psychopathology to study causal mechanisms: Unifying issues and research. Journal of Child Psychiatry and Psychology, 44, $1092-1115$.

Sawyer, M. G., Pfeiffer, S., Spence, S. H., Bond, L., Graetz, B., Kay, D., Patton, G., \& Sheffield, J. (2010). School-based prevention of depression: a randomized controlled study of the beyondblue schools research initiative. Journal of Child Psychology and Psychiatry, 51, 199 - 209. doi:10.1111/j.1469-7610.2009.02136.x

Shochet, I. M., Dadds, M. R., Holland, D., Whitefield, K., Harnett, P. H., \& Osgarby, S. M. (2001). The efficacy of a universal school-based program to prevent adolescent depression. Journal of Clinical Child Psychology, 30, 303-315.Sitarenios, G., \& Kovacs, M. (1999). Use of the Children's Depression Inventory. In M. E. Maruish (Ed.), The use of psychological testing for treatment planning and outcomes assessment (2nd ed., pp. 267-298). Mahwah, NJ: Erlbaum.

Stevens, S.E., Hynan, M.T., \& Allen, M. (2000). A meta-analysis of common factor and specific treatment effects across the outcome domains of the Phase Model of Psychotherapy. Clinical Psychology: Science and Practice, 7, 273-290.

Stice, E., Rohde, P., Gau, J. M., \& Wade, E. (2010). Efficacy trial of the brief cognitivebehavioral depression prevention program of high-risk adolescents: effects at 1- and 2-year follow-up. Journal of Consulting and Clinical Psychology, 78, 856-867. doi: $10.1037 / \mathrm{a} 0020544$

Stice, E., Rohde, P., Seeley, J. R., \& Gau, J. M. (2008). Brief cognitive-behavioral depression prevention program for high-risk adolescents outperforms two alternative interventions: a randomized efficacy trial. Journal of Consulting and Clinical Psychology, 76, 595-606. doi: 10.1037/a0012645 
Stice, E., Rohde, P., Seeley, J. R., \& Gau, J. M. (2010). Testing mediators of intervention effects in randomized controlled trials: an evaluation of three depression prevention programs. Journal of Consulting and Clinical Psychology, 78, 273 - 280. doi: $10.1037 / \mathrm{a} 0018396$

Stice, E., Shaw, H., Bohon, C., Marti, C. N., \& Rohde, P. (2009). A meta-analytic review of depression prevention programs for children and adolescents: Factors that predict magnitude of intervention effects. Journal of Consulting and Clinical Psychology, 77, 486-503. doi: 10.1037/a0015168

Sukhnandan, L., Lee, B., \& Kelleher, S. (2000). An investigation into gender differences and achievement: Phase 2. School and classroom strategies. Slough, England: National Foundation for Educational Research.

The Treatment for Adolescents with Depression Study Team (2003). Treatment for Adolescents with Depression Study (TADS): Rationale, design, and methods. Journal of the American Academy of Child and Adolescent Psychiatry, 42, 531-542. doi: 10.1097/01.CHI.0000046839.90931.0D

Twenge, J. M., \& Nolen-Hoeksema, S. (2002). Age, gender, race, socioeconomic status, and birth cohort differences on the Children's Depression Inventory: A meta-analysis. Journal of Abnormal Psychology, 111, 578-588. doi: 10.1037//0021-843X.111.4.578 Warrington, M., \& Younger, M. (2003). 'We decided to give it a twirl': Single-sex teaching in English comprehensive schools. Gender and Education, 15, 339-350. 
Table 1

Sample Demographics

\begin{tabular}{|c|c|c|c|}
\hline & $\begin{array}{c}\text { CB } \\
(n=166)\end{array}$ & $\begin{array}{c}\text { NSp } \\
(\mathrm{n}=175)\end{array}$ & $\begin{array}{c}\text { NIC } \\
(n=177)\end{array}$ \\
\hline $\mathrm{M}(\mathrm{SD})$ & $15.13(0.75)$ & $15.05(0.66)$ & $15.07(0.85)$ \\
\hline Sex (females) & $102(61.5 \%)$ & $108(61.7 \%)$ & $115(65.0 \%)$ \\
\hline \multicolumn{4}{|l|}{ Race/Ethnicity } \\
\hline Caucasian & $125(75.3 \%)$ & $116(66.7 \%)$ & $136(76.4 \%)$ \\
\hline African-American & $18(10.8 \%)$ & $34(19.5 \%)$ & $24(13.5 \%)$ \\
\hline Latino & $8(4.8 \%)$ & $10(5.7 \%)$ & $10(5.6 \%)$ \\
\hline Asian/Pacific Islander & $3(1.8 \%)$ & $2(1.1 \%)$ & $2(1.1 \%)$ \\
\hline Native American & $1(0.6 \%)$ & $2(1.1 \%)$ & $1(0.6 \%)$ \\
\hline Mixed Heritage & $9(5.4 \%)$ & $9(5.2 \%)$ & $5(2.8 \%)$ \\
\hline Other & $2(1.2 \%)$ & $1(0.6 \%)$ & $0(0.0 \%)$ \\
\hline Sessions attended & $8.5(2.3)$ & $8.6(2.0)$ & - \\
\hline Range & $1-10$ & $0-10$ & -- \\
\hline
\end{tabular}

$\mathrm{CB}=$ Cognitive-Behavioral intervention; $\mathrm{NSp}=$ Nonspecific Control; $\mathrm{NIC}=$ No Intervention Control 
Table 2

Estimated Correlations and Means of Children's Depression Inventory (CDI) Scores by Condition and Time Point

\begin{tabular}{|l|c|c|c|c|c|c|c|}
\hline & $\begin{array}{c}\text { Post- } \\
\text { intervention }\end{array}$ & $\begin{array}{c}\text { 4-month } \\
\text { follow-up }\end{array}$ & $\begin{array}{c}8 \text {-month } \\
\text { follow-up }\end{array}$ & $\begin{array}{c}12-\text { month } \\
\text { follow-up }\end{array}$ & $\begin{array}{c}\text { CB (n = 140) } \\
M(S D)\end{array}$ & $\begin{array}{c}\text { NSp (n = 151) } \\
M(S D)\end{array}$ & $\begin{array}{c}\text { NIC (n = 152) } \\
M(S D)\end{array}$ \\
\hline Baseline & $.44^{* *}$ & $.64^{* *}$ & $.56^{* *}$ & $.49^{* *}$ & $10.30(8.25)$ & $11.38(8.37)$ & $10.79(8.83)$ \\
\hline Post-intervention & -- & $.42^{* *}$ & $.42^{* *}$ & $.34^{* *}$ & $14.55(12.29)$ & $16.14(10.88)$ & $12.41(10.46)$ \\
\hline 4-month follow-up & & -- & $.70^{* *}$ & $.63^{* *}$ & $7.86(7.72)$ & $10.11(8.02)$ & $10.39(8.97)$ \\
\hline 8-month follow-up & & & -- & $.62^{* *}$ & $7.90(7.72)$ & $9.21(8.63)$ & $8.07(7.94)$ \\
\hline 12-month follow-up & & & & -- & $8.40(8.94)$ & $8.66(7.82)$ & $8.38(8.50)$ \\
\hline
\end{tabular}

Note. $\mathrm{CB}=$ Cognitive-Behavioral intervention; $\mathrm{NSp}=$ Nonspecific control intervention; $\mathrm{NIC}=$ No Intervention control; $* * p<.01$. 
Online Supplement

Content of the Cognitive-Behavioral and Nonspecific Control Programs

\begin{tabular}{|c|c|c|c|}
\hline \multicolumn{4}{|c|}{ Cognitive-Behavioral Program (LARS\&LISA) } \\
\hline Session & Topic & Objectives & Content \\
\hline 1 & $\begin{array}{l}\text { Introductions, } \\
\text { Build } \\
\text { Relationships }\end{array}$ & $\begin{array}{l}\text { Explain rules; create a } \\
\text { cooperative atmosphere; } \\
\text { provide overview and } \\
\text { rationale for topics in the } \\
\text { program }\end{array}$ & $\begin{array}{l}\text { - Get to know each other } \\
\text { - Establish basic rules: fairness, support, and a } \\
\text { positive working atmosphere } \\
\text { - Consequences for rule-breaking } \\
\text { - Introduce program }\end{array}$ \\
\hline 2 & Setting Goals & Identify and develop goals & $\begin{array}{l}\text { - Define goals } \\
\text { - Setting realistic and achievable personal goals }\end{array}$ \\
\hline 3 & $\begin{array}{l}\text { Reversible } \\
\text { Spiral - I }\end{array}$ & $\begin{array}{l}\text { Learn connections among } \\
\text { feelings, thoughts, and } \\
\text { behaviors; teach concepts of } \\
\text { "down" and "up" thoughts }\end{array}$ & $\begin{array}{l}\text { - Define "feelings," "thoughts," and "behavior" } \\
\text { - Reversible Spiral: associations among } \\
\text { feelings, thoughts, and behaviors } \\
\text { - Introduce "down thoughts" (self-critical, } \\
\text { action-blocking) and "up-thoughts" (self- } \\
\text { supportive, helpful) }\end{array}$ \\
\hline 4 & $\begin{array}{l}\text { Reversible } \\
\text { Spiral-II }\end{array}$ & $\begin{array}{l}\text { Identify self-critical, action- } \\
\text { blocking thoughts }\end{array}$ & $\begin{array}{l}\text { - Experience the reversible spiral } \\
\text { - Explore meaning of negative thoughts }\end{array}$ \\
\hline 5 & Think Tank-I & $\begin{array}{l}\text { Question self-critical, action- } \\
\text { blocking thoughts; generate } \\
\text { self-supportive, helpful, } \\
\text { realistic thoughts }\end{array}$ & $\begin{array}{l}\text { - Introduce the "reality check" } \\
\text { - Create one's own counter thoughts (i.e., } \\
\text { realistic "up-thoughts") }\end{array}$ \\
\hline 6 & Think Tank-II & $\begin{array}{l}\text { Learn why self-supportive, } \\
\text { realistic thoughts can be } \\
\text { important and how to } \\
\text { integrate them into one's life }\end{array}$ & $\begin{array}{l}\text { - Review meaning of and rationale for "up } \\
\text { thoughts" } \\
\text { - Identify daily situations in which "up } \\
\text { thoughts" can be integrated }\end{array}$ \\
\hline 7 & Just Do It - I & $\begin{array}{l}\text { Learn differences among } \\
\text { assertive, passive, and } \\
\text { aggressive behaviors and } \\
\text { their consequences. Review } \\
\text { connections between thoughts } \\
\text { and behavior }\end{array}$ & $\begin{array}{l}\text { - Identify signs of assertive, passive, } \& \\
\text { aggressive behavior } \\
\text { - Discuss pros and cons of different behaviors } \\
\text { - Explore associations among negative } \\
\text { thoughts, counter thoughts, assertive, passive, } \\
\text { and aggressive behaviors }\end{array}$ \\
\hline
\end{tabular}


PREVENTION OF DEPRESSION 26

\begin{tabular}{|c|c|c|c|}
\hline 8 & Just Do It-II & $\begin{array}{l}\text { Practice assertive behavior } \\
\text { Practice not avoiding }\end{array}$ & $\begin{array}{l}\text { - Demonstrate assertive behaviors } \\
\text { - Practice assertive behavior in role-plays }\end{array}$ \\
\hline 9 & $\begin{array}{l}\text { Making } \\
\text { Contact-I }\end{array}$ & $\begin{array}{l}\text { Learn how to build and } \\
\text { maintain friendships }\end{array}$ & $\begin{array}{l}\text { - Demonstrate verbal and nonverbal strategies } \\
\text { to signal interest in others } \\
\text { - Role-play "making contact" }\end{array}$ \\
\hline 10 & $\begin{array}{l}\text { Making } \\
\text { Contact-II }\end{array}$ & $\begin{array}{l}\text { Practice building friendships. } \\
\text { Obtain feedback about the } \\
\text { program }\end{array}$ & $\begin{array}{l}\text { - Participants evaluate and provide feedback } \\
\text { - Hand out certificates of program completion } \\
\text { - Good-byes and celebration }\end{array}$ \\
\hline \multicolumn{4}{|c|}{ Nonspecific Control Condition } \\
\hline Session & Topic & Objectives & Content \\
\hline 1 & $\begin{array}{l}\text { Introductions to } \\
\text { the program and } \\
\text { each other }\end{array}$ & $\begin{array}{l}\text { Explain rules; create a } \\
\text { cooperative atmosphere; } \\
\text { provide an overview of the } \\
\text { content of the program }\end{array}$ & $\begin{array}{l}\text { - Get to know each other } \\
\text { - Establish basic rules: fairness, support, and a } \\
\text { positive working atmosphere } \\
\text { - Consequences for rule-breaking } \\
\text { - Introduce program }\end{array}$ \\
\hline 2 & Goals & Define and develop goals & - What is a goal? Goals we have in common. \\
\hline 3 & Feelings I & Learn about feelings & - What are feelings? Which feelings do I know? \\
\hline 4 & Feelings II & $\begin{array}{l}\text { Learn about others' } \\
\text { feelings }\end{array}$ & $\begin{array}{l}\text { - How do I know how others feel? } \\
\text { - What makes me feel... (e.g., sad)? }\end{array}$ \\
\hline 5 & Opinions & $\begin{array}{l}\text { Learn about subjective and } \\
\text { objective opinions }\end{array}$ & $\begin{array}{l}\text { - What are opinions? } \\
\text { - Who influences our opinions? }\end{array}$ \\
\hline 6 & Expectations & $\begin{array}{l}\text { Learn about the influence } \\
\text { of expectations }\end{array}$ & $\begin{array}{l}\text { - Who expects something of me? } \\
\text { - Can I meet others' expectations? }\end{array}$ \\
\hline 7 & Communication & $\begin{array}{l}\text { Learn about verbal and } \\
\text { nonverbal communication }\end{array}$ & $\begin{array}{l}\text { - What is nonverbal communication? } \\
\text { - Verbal \& nonverbal communication }\end{array}$ \\
\hline 8 & Making contact & $\begin{array}{l}\text { Learn about first } \\
\text { impressions and different } \\
\text { levels of knowing someone }\end{array}$ & $\begin{array}{l}\text { - What goes into a first impression? } \\
\text { - Types of people we meet in different situations } \\
\text { - How much do we know about others? }\end{array}$ \\
\hline 9 & Friendship & Discuss "friendship" & $\begin{array}{l}\text { - What is "friendship"? What is a good friend? } \\
\text { - Why we select the friends we do }\end{array}$ \\
\hline 10 & $\begin{array}{l}\text { Closing and } \\
\text { Goodbyes }\end{array}$ & $\begin{array}{l}\text { Obtain feedback about the } \\
\text { program; Good-byes and } \\
\text { celebration }\end{array}$ & $\begin{array}{l}\text { - Participants evaluate and provide feedback } \\
\text { about the program } \\
\text { - Hand out certificates of program completion }\end{array}$ \\
\hline
\end{tabular}

